\title{
Latin American Society for Pediatric Research (LASPR) Selected Abstracts From the L Annual Meeting
}

\author{
Buenos Aires, Argentina \\ October 21-24, 2012 \\ Carlos Grandi (Argentina), President \\ Gerardo Weisstaub (Chile), President Elect \\ Fernando Ferrero (Argentina), General Secretary
}

Sponsorship Statement

The publication of the selected meeting abstracts was funded by the Latin American Society for Pediatric Research to promote development across disciplines and to improve pediatric care in the region (http://www.slaip.org.ar).

doi:10.1038/pr.2012.181

1

SEA LEVEL POSTNATAL EXPOSURE MODIFIES THE PULMONARY ARTERIAL PRESSURE, REACTIVITY AND REMODELING IN NEONATAL LAMBS BORN IN HIGHLANDS

Ebensperger $\mathrm{G}^{1}$, Santos $\mathrm{D}^{1}$, Aburto $\mathrm{C}^{1}$, Ramos $\mathrm{M}^{1}$, Araya $\mathrm{C}^{1}$, Hernández $\mathrm{I}^{1}$, Moraga FA³ ${ }^{3}$, Herrera $\mathrm{EA}^{1,2}$, Reyes RV $\mathrm{R}^{1}$, Llanos $\mathrm{AJ}^{1,2}$

${ }^{1}$ Facultad de Medicina; ${ }^{2}$ INCAS, Universidad de Chile; ${ }^{3}$ Facultad de Medicina, Universidad Católica del Norte, Chile

Background: Neonates born at high altitude developed pulmonary arterial hypertension due to increased vascular tone and vascular remodeling. We hypothesized that exposure to sea level changes pulmonary arterial pressure (PAP), vascular reactivity and vascular remodeling in the pulmonary arteries. Methods: We studied 3 groups of NB lambs, 7 of them gestated, born and kept $(3,600 \mathrm{~m})$ in Putre (HAHA); $10 \mathrm{NB}$ from Putre brought down to Lluta (60m) at 2-3 days after birth (HALA) , and 5 NB lambs gestated, born and kept at sea level (LALA). In all, we measured PAP daily (Swan-Ganz catheter) and at 16 days underwent euthanasia to determine small pulmonary artery reactivity to vasoconstrictors ( $\mathrm{KCl}$ and endothelin-1) and vasodilators (fasudil, ROCK inhibitor and sildenafil, PDE5 inhibitor) by wire myography. Furthermore, we assessed the percentage of smooth muscle cells layer (van Gieson staining) of small pulmonary arteries.

Results: The HALA group had a marked PAP decrease, comparable to LALA group, and significantly lower than the Putre group (HAHA) $(\mathrm{p}<0.001)$. The HALA group had a decreased vasoconstriction $(\mathrm{KCl}, \mathrm{ET}-1)$ in relation to HAHA group $(\mathrm{p}<0.05)$, whereas no changes were observed in vasodilators (fasudil, sildenafil). Regarding the smooth muscle cells layer, the HALA and LALA had significantly reduced this layer compared to HAHA neonates $(\mathrm{p}<0.05)$.

Conclusion: Postnatal oxygenation at sea level markedly reduced the pulmonary arterial pressure, vasoconstrictor responses and smooth muscle layer in the small pulmonary arteries in neonates brought down from high altitude.

Funding: FONDECYT 1090355, 1120605, 1110595-Chile.

\section{2}

IMPACT OF A CLINICAL RULE FOR THE INITIAL MANAGEMENT OF CHILDREN WITH PNEUMONIA ON ANTIBIOTIC USE: A RANDOMIZED CONTROLLED TRIAL Torres F, Pasarelli I, Cutri A, Ossorio MF, Ferrero F

Hospital de Niños Pedro de Elizalde, Buenos Aires, Argentina

Background: Pneumonia is an important cause of morbidity and mortality in childhood. Although more than half of the cases are due to viruses, difficulty in ruling-out bacterial infection leads to a systematic use of antibiotics. A clinical prediction rule (BPS: Bacterial Pneumonia Score) identifies children with pneumonia that would not benefit from the antibiotics use.

Objective: To evaluate if the use of the BPS for the initial management of patients with pneumonia reduces use of antibiotics, compared to managing this disease according to current guidelines. Methods: Randomized, controlled trial, partially masked, comparing the use of antibiotics for pneumonia in children 3-60 months old, in an outpatient setting, according to 2 different methods of initial management. Patients were randomized to be managed according to BPS (antibiotic indication if BPS $\geq 4$ points) or current guidelines (use of antibiotics at the discretion of the treating physician, based on institutional guidelines). We calculated the proportion of antibiotic use in each group and evaluated the clinical outcome.

Results: 120 patients (60 BPS group and 60 control group), 63 males, mean age $24.2 \pm 14.1$ months. The use of antibiotics was significantly lower in the BPS group ( $46.6 \%$ vs. 86.6 ; OR: $0.13 ; 95 \% \mathrm{Cl}$ $0.05-0.35, \mathrm{P}<0.001)$. Poor outcome was observed in 10 patients $(8.3 \%), 5$ in each group $(\mathrm{p}=1.0$; OR: 1,0 IC95\%: 0,2-3,6)

Conclusion: The use of antibiotics was significantly lower in the group treated according to the BPS, wit out increasing treatment failure.

NCT01041209
3

TYPE OF DELIVERY AND INDICATORS OF ADIPOSITY IN YOUNG ADULTS

Mesquita DN, Barbieri MA, Cardoso VC, Silva AAM, Goldani MZ, Bettiol H FMRP-USP, UFMA, UFRGS, Brazil

Background: The contribution of type of delivery to the occurrence of obesity measured by body mass index has been reported, and is probably due to changes in the intestinal microbiota provoked by cesarean section, affecting the metabolism and accumulation of energy in the hos and predisposing the individual to fat accumulation. Studies associating type of delivery with other indicators of adiposity are still scarce.

Objective: To evaluate the association of cesarean delivery with indicators of adiposity in young adults.

Methodology: The study was conducted on 2063 young individuals aged 23 to 25 years belonging to the 1978/79 birth cohort of Ribeirão Preto, SP, Brazil. Type of delivery was the independent variable. The following anthropometric measurements were used as indicators of adiposity: waist circumference (WC), weight-height ratio (WHTR), waist-hip ratio (WHR), tricipital skinfold (TSF), and subscapular skinfold (SSF). The association between cesarean delivery and indicators of increased adiposity was evaluated after adjustment for birth and young adulthood variables in a Poisson model with robust adjustment of variance, with a $95 \%$ confidence interval $(95 \% \mathrm{CI})$. Results: The prevalence of cesarean delivery in this cohort was $32 \%$. The prevalence of increased WC, WHTR, WHR, TSF and SSF was $32.1 \%, 33.0 \%, 15.2 \%, 10 \%$ and $9.4 \%$, respectively. After adjustment, the relative risks of cesarean delivery regarding the indicators of increased adiposity were: 1.28 for WC (95\%CI 1.12-1.46), 1.29 for WHTR ( $95 \% \mathrm{CI} 1.10-1.53), 1.53$ for WHR $(95 \% \mathrm{Cl}$ $1.24-1.89), 1.43$ for TSF (95\%CI 1.07-1.87), and 1.48 for SSF (95\%CI $1.10-1.98)$.

Conclusion: The risk for increased adiposity was higher among subjects born by cesarean delivery compared to subjects born by vaginal delivery.

\section{4}

\section{MATERNAL OBESITY AS A RISK FACTOR FOR BIRTH DEFECTS} Grandi $\mathrm{C}^{1}$ Maccarone $\mathrm{MB}^{2}$, Rittler $\mathrm{M}^{2}$

${ }^{1}$ Consejo de Investigación en Salud, ${ }^{2}$ Hospital Maternoinfantil Sardá, Buenos Aires, Argentina Introduction: Our aim was estimate the risk of birth defects associated with prepregnancy maternal obesity.

Methods: case-control study including several birth defects using data from the Perinatal Informatic System of Hospital Sardá, between 1995-2000. Mothers who delivered a live infant with and without birth defects were included; and maternal body mass index (BMI) was calculated. The risks of birth defects for overweight women (BMI $25.0-29.9 \mathrm{~kg} / \mathrm{m} 2$ ) and obese women (BMI $\geq 30$ ) were compared with those for normal weight women (BMI <25.0).

Results: 18,098 mothers-infants pairs were included. Prevalence of overweight was $25.6 \%$ and obesity $10.2 \%$. Prevalence of birth defects was $2.57 \%$ (95\% CI 2.35-2.82) and, according to BMI it was $2.61 \%$ in normal weight women, $2.31 \%$ overweight women and $3.04 \%$ in obese women (chi2 for lineal trend $\mathrm{p}=0.692$ ). Demographic, obstetric and neonatal characteristics were quite similar between cases and controls. Compared with normal weight women, crude risks for birth defect were 0.88 (I95 \% CI 0.70-1.11) and 1.17 (0.87-1.58) for overweight and obese women, respectively; after adjusting for potential confounders, no differences were found. Maternal age showed a scarcely increase in the risk, whereas maternal education and gestational age were associated with a protective effect.

Conclusions: Despite prevalence of overweight and obesity were high in our population, our study do not confirmed the previously observed association between birth defects and pre-pregnancy maternal obesity. 


\section{5}

RACECADOTRIL, A GOOD ALTERNATIVE IN THE MANAGEMENT OF ACUTE WATERY DIARRHEA IN CHILDREN

Torrez J, Soria R, Grandy G

Pediatric Center Albina Patiño, Cochabamba, Bolivia

Objective: To determine the efficacy of racecadotril in the treatment of acute watery diarrhea in children under 5 years old.

Design: randomized, double-blind, controlled trial including children aged 6 to 59 months, hospitalized for acute diarrhea. Children were randomized to receive oral rehydration solution plus placebo or oral rehydration solution plus racecadotril. The primary outcome was duration of diarrhea. Secondary outcomes were stool weight, length of stay, duration of fever and vomiting. Results: 53/111 children completed the study. Baseline characteristics were similar in both groups. The median duration of diarrhea was 46.5 hours in the control group (C) and 34 hours in the racecadotril group $(\mathrm{R})(\mathrm{p}=0.01)$. The number and weight of stools was statistically lower in R group $(p<0.0001)$. Length of stay was longer in the control group $(64.5$ hs vs. $46 \mathrm{hs} ; \mathrm{p}=0.03)$. There were no differences regarding duration of fever or vomiting.

Conclusions: The use of racecadotril decreased the duration and magnitude of acute watery diarrhea in children.

NCT01577043

\section{6}

RISK OF MICROBIOLOGICAL CONTAMINATION BETWEEN SAMPLES OF HUMAN MILK OBTAINED AT HOME AND OBTAINED AT HOSPITAL

Serra $\mathrm{V}^{1}$, Ossorio $\mathrm{F}^{2}$, Aguilar $\mathrm{N}^{1}$, Teves $\mathrm{S}^{3}$, Lopez de Volder A $\mathrm{A}^{3}$, Armadans $\mathrm{M}^{1}$

${ }^{1}$ Servicio de Neonatología, IADT; ${ }^{2}$ Departamento de Pediatría, UBA; ${ }^{3}$ Facultad de Farmacia y Bioquímica, UBA, Buenos Aires, Argentina

Background: Human milk is the best option for feeding premature infants. Due to their inadequate suction/swallowing capacity, human milk is usually administrated using oro-gastric feeding tubes. However, there is little information regarding microbiologic safety of human milk.

Objective: We aim to evaluate if is there any difference in human milk contamination regarding the place of extraction (house or hospital). We also explore the possible association between milk contamination and feeding intolerance.

Methods: Cross-sectional study including pairs of human milk samples (one sample obtained at home and one sample obtained at hospital) from mothers of hospitalized preterm babies (gestational age $\leq 35$ weeks). We considered contamination when milk samples showed more than $10^{5} \mathrm{CFU}$ $\mathrm{ml}$ mesophiles, presence of Escherichia coli, enterobacteria, Staphylococcus aureus, Pseudomonas, Salmonella, Streptococcus faecalis, and/or molds and yeast.

Results: We analyzed 280 human milk samples (140 pairs) obtained from 53 women; 139 samples (49.6\%; 95\%CI: 43.6-55.6) showed contamination, being more frequent among home obtained samples than among hospital obtained samples ( $59.6 \%$ vs. $39.6 \%$; $\mathrm{p}=0.0008$; OR: $2.25 ; 95 \% \mathrm{CI} 1.36-3.7)$.

There were no differences in the contamination rate between samples from women whose children presented feeding intolerance and those who did not $(53.1 \%$ vs. $49.6 \%$; $\mathrm{p}=0.7$; OR: $1.1595 \% \mathrm{Cl}$ $0.52-2.56)$

Conclusion: Almost half of human milk samples showed microbiologic contamination, being more frequent among home obtained samples. There were no differences in contamination rate in human milk samples between those who developed feeding intolerance and those who did not.

\section{7}

EVOLUTION OF NUTRITIONAL STATUS AND RISK FOR METABOLIC SYNDROME IN SCHOOLCHILDREN OF PORTO ALEGRE, BRAZIL: FOLLOW-UP OF 4 YEARS Santos $\mathrm{NS}^{1}$, Costa RF${ }^{1}$, Nogueira $\mathrm{RC}^{2}$, Meyer $\mathrm{F}^{2}$, Kruel LFM

${ }^{1}$ Grupo de Pesquisa em Atividades Aquáticas e Terrestre (GPAT), and ${ }^{2}$ Grupo de Pesquisa em Medicina do Esporte em Pediatria, ESEF-UFRGS, Porto Alegre, Brazil

Introduction: Obesity in childhood and adolescence is a public health problem worldwide, both for risk of its maintenance until adulthood as the early onset of chronic diseases.

Objective: To verify the evolution of nutritional status and risk of metabolic syndrome in children over four years.

Methods: The study included 235 children (38.7\% male), whose nutritional status was evaluated in 2008 and 2012 in the schools of Porto Alegre, Brazil. In the first assessment, the students were aged between 7 and 10 years old $(8.9 \pm 1.05)$, and in the second between 10 and 14 years old $(12.3 \pm 1.05)$. Assessment included weight, height and waist circumference. Nutritional status was estimated by BMI for age and gender (WHO, 2007), and the risk for metabolic syndrome by the waist-to-height ratio, with local cutoff points (Costa et al, 2012).

Results: For boys, underweight remained at $1.1 \%$ in both surveys, overweight increased from $13.2 \%$ to $16.5 \%$ and obesity from $12.1 \%$ to $17.6 \%$. For girls, underweight increased from $0 \%$ to $2.1 \%$, overweight decreased from $19.4 \%$ to $14.6 \%$, and obesity increased from $13.2 \%$ to $20.1 \%$. Although there was no statistical difference between two periods, $19.8 \%$ of boys and $18.7 \%$ of girls worsened their nutritional status. The risk for metabolic syndrome increased from $6.6 \%$ to $7.7 \%$, and $9.7 \%$ to $13.9 \%$ among boys and girls, respectively.

Conclusion: Results showed a trend of increasing prevalence of obesity and risk for metabolic syndrome in the transition from childhood to adolescence.

Funding: CNPq - Process No. 159754/2010-0
8

VARIATION IN SODIUM SERUM LEVELS USING TWO DIFFERENT INTRAVENOUS MAINTENANCE FLUIDS IN APPENDECTOMY POSTSURGICAL HOSPITALIZED CHILDREN

Dicembrino M, Anderson M, Jorro Barón F, Perez L, Vely AG, Viegas Demarco M Docencia e Investigación, Hospital de Niños Pedro de Elizalde, Buenos Aires, Argentina Background: Hyponatremia is common among hospitalized children, especially during the postsurgical period.

Objective: To compare the variation in serum sodium in post appendectomy hospitalized children, receiving two different intravenous maintenance fluids.

Methods: Randomized, controlled trial. Appendectomy postsurgical patients were assigned one of two maintenance intravenous (IV) fluids: $0.3 \% \mathrm{NaCl}(\mathrm{Na} 50)$ or $0.45 \% \mathrm{NaCl}(\mathrm{Na} 70)$ both with dextrose $5 \%$ at standards rates, exclusively, for 12 hours. Venous blood samples to estimate serum sodium levels were obtained at baseline and 12 hours after fluid administration

Results: 78 patients were included: 42 in group "Na50" and 36 in group "Na70". In the first group the initial sodium level was $139.9 \pm 1 \mathrm{mEq} / \mathrm{L}$ and the final one $138.1 \pm 1.3 \mathrm{mEq} / \mathrm{L}$, showing a 1.83 $\mathrm{mEq} / \mathrm{L}$ decrease $(\mathrm{p}=0.03)$; in the latter, the initial sodium level was $138.1 \pm 1.2 \mathrm{mEq} / \mathrm{L}$ and the final one $138.2 \pm 1.6 \mathrm{mEq} / \mathrm{L}$, showing a $0.15 \mathrm{mEq} / \mathrm{L}$ increase $(\mathrm{p}=0.87$ ). When comparing both final sodium levels, the difference was no significant $(\mathrm{p}=0,370)$. No adverse effects due to IV fluids administration were observed.

Conclusions: Despite there was no difference in the final natremia between both groups, using lower tonicity IV maintenance fluids showed a significant decrease in sodium levels while using higher tonicity fluids did not modify them.

NCT01251770

\section{9}

\section{NEONATAL HEART RATE MEASUREMENT AND ANALYSIS SYSTEM}

Cuestas E, Rivata L, Juri G

Facultades de Ciencias Médicas y Ciencias Exactas, Universidad Nacional de Córdoba, Argentina

Background: Neonatal sepsis can often lead to death. The analysis of the hearth rate (HR) variability using Approximate Entropy (ApEn), allows predicting sepsis 24 hours prior to clinical manifestations.

Objective: We aim to design a compact, autonomous and functional electronic device that could perform data acquisition and subsequent analysis in real time, in order to predict neonatal sepsis using HR variability analysis.

Methods: HR is measured each 25 minutes, and ApEn calculated from these values. The device captures and digitalizes the D1 EKG signal, acquireing the values required to calculate ApEn. A microcontroller includes the algorithm allowing real-time calculation. The user can access the information obtained in the last 24 hours.

Conclusions: This device could help manage neonates by identifying earlier those at high risk of developing neonatal sepsis.

\section{0}

THE CONTRADICTORY EFFECT OF BMI ON ADULT BLOOD PRESSURE THROUGHOUT LIFE

Cardoso VC, Ferraro AA, Grandi C, Silva AAM, Bettiol H, Barbieri MA

FMRPUSP, Brazil

Background: Chronic diseases (CD) are associated not only with risk factors from adulthood but also with predictors that occurred decades before the onset of disease. Hypertension (HT) is the most prevalent CD. Recently, it has been suggested that pre-hypertension (PHT: systolic pressure $120-140$ of $\mathrm{mm} \mathrm{Hg}$ and/or diastolic pressure $80-90 \mathrm{~mm} \mathrm{Hg}$ ) is linked to a higher health risk.

Aims: The objective of this study is to assess the independent association of body mass index (BMI) measured in three points in the life cycle with adult PHT and HT.

Methods: A prospective cohort of all living born of the city of Ribeirao Preto, Brazil, was assessed at birth (1978/79), school-age (1987/88) and adulthood (2002/04). Data on neonatal variables, socioeconomic status and anthropometry at all three moments as well as adult risk factors for HT were available for 1143 of the 6484 eligible subjects. Conditional weight analysis was performed to assess the risk of repeated-in-time measurements.

Results: Lower BMI at birth was associated with diastolic HT (RR=3.10; 95\%CI 1.08-8.88) Higher BMI at school age was linked with adult diastolic PHT and HT (respectively RR=2.78 95\%CI 1.67-4.64 and RR=6.79; 95\%CI 1.82-25.46). Higher adult BMI was associated with both systolic PHT and HT (respectively RR=2.29; 95\%CI 1.57-3.34 and RR=4.68; 95\%CI 2.34-9.36) and diastolic PHT and HT (respectively RR=2.37; 95\%CI 1.43-3.82 and RR=14.94; 95\%CI 3.42 64.67). These effects were significant after adjustments for traditional HT risk factors and possible confounders.

Conclusion: BMI throughout the life cycle has an independent, albeit contradictory, effect on adult HT. 
11

GASTROSCHISIS (GQ): GROWTH AND DEVELOPMENT AT TWO YEARS OF LIFE

Andres S, Bauer G, Rabasa C, Novali L, Fariña D

Hospital Garrahan, Buenos Aires, Argentina

Introduction: Incidence of GQ increased in the latest decades. Many patients developed a complicate neonatal evolution, with little information about their outcome.

Objective: To evaluate the outcome of a GQ cohort, at 2 years of age.

Method: A prospective cohort of patients diagnosed with GQ, discharged from NICU between January 2008 and July 2010, followed for 2 years. Main outcomes: morbidity (hospitalizations) growth (Z score) and development (CAT-CLAMS scale, CD <70)

Results: 56 GQ patients were discharged from NICU, 12 of them were referred to other NICUs and 44 entered the follow-up program; from them, 37 (84\%) were followed-up for to 2 years (18 female/12male). The median values of birth-weight was $2450 \mathrm{~g}$ (1600-3000), gestational age $37 \mathrm{sem}$ (33-40), length of stay 53 days (24-210), parenteral nutrition 33 days (12-174).8 patients required at least 1 surgery; 15 (40\%) were hospitalized during the first year $(8$ of them due to acute respiratory infection, 5 due to bowel suboclution. Weight $Z$ score was $-2.10 \pm 0,93$ at NICU discharge, $-0.84 \pm$ 0.80 after 1 year, and $-0.58 \pm 1.13$ at 2 years $(\mathrm{p}<0.001)$. Height $Z$ score was $-2.78 \pm 1,32$ at NICU discharge, $-1.06 \pm 1,04$ after 1 year, and $-0.76 \pm 1.28$ at to years $(p=0,003)$. Head circumference $Z$ score was $-1.50 \pm 1,68$ at NICU discharge, $-0.26 \pm 1.08$ after 1 year, and $-0.13 \pm 1.08$ after 2 years (p $<0.001)$.Six patients showed developmental delay.

Conclusion: In our study we observed that, despite of a high morbidity (hospitalizations) and failure to thrive, GQ patients achieved an appropriate growth at 2 years of age. However, up to $20 \%$ of them showed a developmental delay.

\section{2}

MELATONIN MODIFIES CARDIAC FUNCTION IN PULMONARY HYPERTENSIVE NEONATES

Torres $\mathrm{F}^{1}$, Santos $\mathrm{D}^{1}$, Diaz $\mathrm{M}^{1}$, Chubretovic $\mathrm{M}^{1}$, Montt $\mathrm{C}^{1}$, Reyes $\mathrm{RV}^{1}$, Serón-Ferré $\mathrm{M}^{1}$, Llanos $\mathrm{A}^{1,2}$, Herrera $\mathrm{E}^{1,2}$

${ }^{1}$ Physiopathology Program, Faculty of Medicine, ${ }^{2}$ International Center for Andean Studies (INCAS), University of Chile, Chile

Background: Lambs gestated and born at high altitude develop cardiopulmonary alterations (Herrera et al. Am J Physiol. 292:R2234, 2007), such as right ventricular hypertrophy. Hypoxia and oxidative stress are crucial etiological factors in this condition. Melatonin is a neurohormone with antioxidant properties. Therefore, we hypothesized that postnatal administration of melatonin may revert the cardiopulmonary changes in these neonates.

Methods: Newborn lambs, gestated and born in high altitude $(3.600 \mathrm{~m})$, were treated with melatonin $(n=5,1 \mathrm{mg} / \mathrm{Kg} /$ day $)$ or vehicle $(\mathrm{n}=5)$ for 7 days. During treatment cardiovascular variables were measured, such as cardiac output, heart rate, pulmonary arterial pressure (PAP), systemic arterial pressure and pulmonary vascular resistance (PVR). Further, heart rate variability (HRV) was determined. At the end of treatment a graduated oxygenation/hypoxia experiment was performed, recording the same CV variables. After euthanasia, cardiac samples were extracted for morphometric and antioxidant enzyme activity (SOD, CAT) determinations.

Results: Melatonin group showed an early fall in PAP and PVR. In response to changes in oxygenation, the melatonin group showed a greater HR and higher stability in HRV. Melatonin increased the low frequency $(46.3 \pm 3,2$ vs. $33.2 \pm 3,8, \mathrm{P}<0.05)$ and decreased the high frequency $(24.3 \pm 2,2$ vs. $41.3 \pm 3,1, \mathrm{P}<0.05)$ component in the HRV. There were no differences in the cardiac morphometric analysis or in the cardiac antioxidant enzyme activities.

Conclusion: Melatonin induce an early fall in PAP and PVR, improving cardiopulmonary function. This was associated with a cardiac autonomic sympathetic predominance.

Funding: FONDECYT 1110595, 1090355 and 1120605, Chile

\section{3}

ASSOCIATION BETWEEN VISCERAL ADIPOSITY VERSUS GENERAL OBESITY WITH METABOLIC ABNORMALITIES IN PREPUBERTAL AND PUBERTAL OBESE CHILDREN Sepúlveda CA, Espinoza AG, Le Roy CO, Rebollo MJ, Castillo-Durán C

Dept. Nutrition and Dietetics, U del Desarrollo, Institute of Nutrition and Food Technology (INTA), Dept. of Pediatrics, Fac. Medicine, U de Chile, Hospital San Borja Arriarán.

Background: Childhood obesity is associated with early onset of risk factors for chronic diseases in adulthood, but it is unknown if visceral obesity markers are better associated to metabolic related disorders than general obesity markers, in children.

Objective: To evaluate the association between general or visceral obesity with metabolic abnormalities in prepubertal and pubertal obese children.

Methods: We studied 76 obese children (BMI $\geq 95$ percentile of WHO standards, $6-15$ years, both genders), without chronic diseases. We evaluated: weight, height, waist circumference (WC), pubertal stage, visceral adiposity (VA) with abdominal ultrasonography (segment rectus abdominus-spina and liver echogenicity). Measurements: insulinemia, glycemia, serum lipids.

Results: $43.4 \%$ presented insulin resistance (IR), $48.7 \%$ fatty liver (NALFD), 38.2\% triglycerides $\geq 100 \mathrm{mg} / \mathrm{dL}$ (HTG) and $32.8 \% \mathrm{HDL}-\mathrm{c} \leq 40 \mathrm{mg} / \mathrm{dL}$. In $67 / 76$ subjects WC was increased; $44.7 \%$ showed IR; $50.5 \%$ NALFD, $35.8 \% \mathrm{HTG}$, and $34.3 \mathrm{c}-\mathrm{HDL} \leq 40 \mathrm{mg} / \mathrm{dL}$ (vs. those with normal WC: NS). Among the $28 / 76$ subjects with normal VA, $7.9 \%$ showed IR, 9.8\% NAFLD, 7.9\% HTG, and 9.2\% c-HDL $\leq$ $40 \mathrm{mg} / \mathrm{dL}$. Among the subjects with increased VA, 35.5\% showed IR, 39.5\% NAFLD, 36\% HTG, and $30.3 \%$ HDL-c $\leq 40 \mathrm{mg} / \mathrm{dL}$ (Kruskal Wallis for each: $\mathrm{p}<0,05$ ). Logistic regression for VA and metabolic measurements showed a $\mathrm{RR}=4.50$ (95\%CI: $1.36-14.81)$ for IR, $\mathrm{RR}=10.3$ (95\%CI: 4.32-41.48) for NAFLD, and RR=4.31 (95\%CI: $1.30-14.26)$ for HTG.

Conclusions: Increased visceral adiposity is more sensitive than waist circumference and BMI to predict metabolic abnormalities, NAFLD and cardiovascular risk factors in obese children and adolescents.
14

INTENSIVE PHARMACOVIGILANCE PROGRAM OF CALCINEURIN INHIBITORS IN PEDIATRIC RENAL AND HEPATIC TRANSPLANT PATIENTS

Riva $\mathrm{N}^{1}$, Cáceres Guido $\mathrm{P}^{1,2}$, Rousseau $\mathrm{M}^{2}$, Ibañez $\mathrm{J}^{3}$, Cambaceres $\mathrm{C}^{4}$, Mato $\mathrm{G}^{2}$, Monteverde $\mathrm{M}^{3}$, Schaiquevich $\mathrm{P}^{2}$

${ }^{1}$ Unidad de Farmacocinética Clínica, ${ }^{2}$ Area de Farmacia, ${ }^{3}$ Unidad de Trasplante Renal, ${ }^{4}$ Unidad de Trasplante Hepático; Hospital de Pediatría Garrahan, Buenos Aires, Argentina

Background: Cyclosporine and tacrolimus are immunosuppressant used for the pharmacological therapy of transplant recipients. Because of their high inter and intra-individual pharmacokinetic variability, narrow therapeutic range and in particular, a documented relationship between the plasma concentration levels and efficacy, these drugs must be closely monitored to assure treatment efficiency. Recently, generic formulations of cyclosporine and tacrolimus have been introduced in the local market.

Methods: Considering the vulnerability of the pediatric population receiving renal or liver transplant, a pharmacovigilance program of cyclosporine and tacrolimus was implemented, evaluating adverse events, drugs levels, clinical and lab factors, and type of formulation. Clinical records were analyzed and adverse events were registered and classified by severity and causality.

Results: A total of 37 patients were analyzed: 21 renal and 16 hepatic transplant patients. Among them, 35 adverse events to cyclosporine and 25 to tacrolimus were recorded. The most frequent adverse events observed was hypertension (14 related to cyclosporine and 6 to tacrolimus), nephrotoxicity ( 5 to cyclosporine and 4 to tacrolimus) and hypomagnesaemia (12 to tacrolimus). A total of $94 \%$ and $96 \%$ of the adverse events registered were probable or definitive related, and classified as moderate or severe intensity.

Conclusion: During this study, we significantly increased the number of reports of adverse events related to calcineurin immunosuppressant. Spontaneous notification of adverse events must be encouraged.

\section{5}

RELATIONSHIP BETWEEN OBESITY DEFINED BY THE PERCENTAGE OF BODY FAT AND DEFINED BY BODY MASS INDEX IN JUJUY SCHOOL CHILDREN

Carrillo $\mathrm{R}^{1}$, Román $\mathrm{EM}^{1}$, Meyer $\mathrm{E}^{2}$, Bejarano $\mathrm{IF}^{1}$, Dipierri JE

${ }^{1}$ INBIAL-UNJU and ${ }^{2}$ PROSANE, Jujuy, Argentina

Background: Obesity $(\mathrm{OB})$ is strongly associated with excess body fat.

Objective: We analyzed the correlation between the prevalence of $\mathrm{OB}$ determined by the percentage of body fat (BF\%) and that obtained by evaluating the BMI, according to international standards.

Methods: Data from 15,541 schoolchildren in Jujuy anthropometrically evaluated in a PROSANE program (2010-2011) were analyzed. They were grouped by gender and two age groups (5 - 6 years old and 11-12 years old). BMI was calculated and the prevalence of $\mathrm{OB}$ was determined as the cutoff points of IOFT, CDC and WHO references. The BF\% was obtained by Deuremberg's $\mathrm{OB}$ equation and boys that exceeded $25 \%$ and girls that exceeded $30 \%$ were considered $\mathrm{OB}$. The kappa index was used to determine the agreement between the prevalence of $\mathrm{OB}$ obtained from the references and the $\mathrm{BF} \%$. Agreement was classified as very good $(>0.80)$, good $(0.61$ to 0.80$)$, moderate ( 0.41 to 0.60$)$, fair $(0.20$ to 0.40$)$ and poor $(\leq 0.20)$.

Results: Differences in the prevalence of OB between $\mathrm{BMI}$ and $\mathrm{BF} \%$ were, in general, all statistically significant but the highest ( $>21 \%$ ) occurred using WHO-BMI standard. Regardless of gender, the agreement was good in all cases except when using WHO-BMI standard, where it was regular.

Conclusion: The OB obtained by IOFT and CDC showed a better relationship with excess body fat determined by the $\mathrm{BF} \%$ than that obtained by the $\mathrm{WHO}$ references.

Funding: PICTO 2008-00139, ANPCyT, Argentina

\section{6}

GEOGRAPHICAL ALTITUDE AND RELATIONSHIP BETWEEN BODY MASS INDEX AND BODY FAT IN JUJUY SCHOOL CHILDREN

Román EM, Carrillo R, Bejarano IF, Alfaro EL, Dipierri JE

INBIAL-UNJU, Jujuy, Argentina

Background: BMI is the most widely used indicator for estimating nutritional condition because of its relationship with the percentage of body fat (BF\%).

Objective: We compared the BF\% (calculated using different equations) with BMI in children and adolescents from different altitude levels in Jujuy.

Methods: We analyzed anthropometric data from 2670 school children (6-17 years) stratified by geographical altitude: Lowlands (LL) $(<2500 \mathrm{~m})$ and Highlands $(\mathrm{HL})(>2500 \mathrm{~m})$. The BF\% was calculated from skinfolds using Siri and Slaughter equations, and BMI with Deuremberg equation. We used the Spearman test to evalaute correlation between BF\% and BMI using SPSS software.

Results: All comparisons were statistically significant and positive. In the Lowlands (LL) the correlation coefficient obtained with Deuremberg's equation was the highest $(0.971)$, followed by Slaughter (0.641) and Siri (0.433); results in the Highlands (HL) were similar. Values obtained with Deuremberg's equation must be carefully interpreted because that equation derives from BMI. Using the other equations that take into account the skin folds, although correlations are statistically significant, only explain $18 \%$ (Siri) and $41 \%$ (Slaughther) of the variation in BMI.

Conclusion: $\mathrm{BMI}$ shows the same correlation with $\mathrm{BF} \%$ regardless of geographic altitude. These results verified studies in other populations, indicating that BMI is an insensitive indicator of changes in adiposity in children and adolescents.

Funding: PICTO 2008-00139, ANPCyT, Argentina 